\title{
B-type Natriuretic Peptide: Perioperative Patterns in Congenital Heart Disease
}

\author{
Matthew F. Niedner, MD, ${ }^{* \dagger \neq}$ Jennifer L. Foley, RN, ${ }^{*}$ Robert H. Riffenburgh, PHD, ${ }^{\dagger}$ \\ David P. Bichell, MD, ${ }^{* \Uparrow}$ Bradley M. Peterson, MD, FCCM, ${ }^{*}$ and Alexander Rodarte, MD, FCCM ${ }^{\star, * *}$ \\ *Department of Pediatric Critical Care, Rady Children's Hospital, 'Department of Pediatrics, Naval Medical Center San \\ Diego, §Department of Mathematics and Statistics, San Diego State University and **Department of Anesthesiology, \\ University of California San Diego, San Diego, Calif., „Division of Pediatric Critical Care, University of Michigan, Ann \\ Arbor, Mich., and "Department of Pediatric Cardiac Surgery, Vanderbilt University, Nashville, Tenn., USA
}

\section{A B S T R A C T}

Objective. B-type natriuretic peptide (BNP) has diagnostic, prognostic, and therapeutic roles in adults with heart failure. BNP levels in children undergoing surgical repair of congenital heart disease (CHD) were characterized broadly, and distinguishable subgroup patterns delineated.

Design. Prospective, blinded, observational case series.

Setting. Academic, tertiary care, free-standing pediatric hospital.

Patients. Children with CHD; controls without cardiopulmonary disease.

Interventions. None.

Measurements. Preoperative cardiac medications/doses, CHD lesion types, perioperative BNP levels, intraoperative variables (lengths of surgery, bypass, cross-clamp), postoperative outcomes (lengths of ventilation, hospitalization, open chest; averages of inotropic support, central venous pressure, perfusion, urine output; death, low cardiac output syndrome (LCOS), cardiac arrest; readmission; and discharge medications).

Results. Median BNP levels for 102 neonatal and non-neonatal controls were 27 and $7 \mathrm{pg} / \mathrm{mL}$, respectively. Serial BNP measures from 105 patients undergoing CHD repair demonstrated a median postoperative peak at 12 hours. The median and interquartile postoperative 24-hour average BNP levels for neonates were $1506(782-3784) \mathrm{pg} / \mathrm{mL}$ vs. $286(169-578) \mathrm{pg} / \mathrm{mL}$ for non-neonates $(P<0.001)$. Postoperative BNP correlated with inotropic requirement, durations of open chest, ventilation, intensive care unit stay, and hospitalization $(\mathrm{r}=0.33-0.65$, all $P<0.001)$. Compared with biventricular CHD, Fontan palliations demonstrated lower postoperative BNP (median 150 vs. $306 \mathrm{pg} / \mathrm{mL}, P<0.001)$, a 3 -fold higher incidence of LCOS $(P<0.01)$, and longer length of hospitalization (median 6.0 vs. 4.5 days, $P=0.01$ ).

Conclusions. Perioperative BNP correlates to severity of illness and lengths of therapy in the CHD population, overall. Substantial variation in BNP across time as well as within and between CHD lesions limits its practical utility as an isolated point-of-care measure. BNP commonly peaks 6-12 hours postoperatively, but the timing and magnitude of BNP elevation demonstrates notable age-dependency, peaking earlier and rising an order of magnitude higher in neonates. In spite of higher clinical acuity, non-neonatal univentricular CHD paradoxically demonstrates lower BNP levels compared with biventricular physiologies.

Key Words. Natriuretic Peptides; Congenital Heart Defects; Congestive Heart Failure; Low Cardiac Output; Perioperative Care; Nesiritide

\section{Introduction}

A $\mathrm{S}$ a diagnostic test, B-type natriuretic peptide (BNP) levels are sensitive and specific for the

Institution where work was performed: Rady Children's Hospital, San Diego, CA, USA. presence and magnitude of congestive heart failure $(\mathrm{CHF})$ in adults and children, being elevated in settings of systolic and diastolic dysfunction, both acute and chronic. ${ }^{1,2} \mathrm{BNP}$ is a prognostic marker for common endpoints in adult and pediatric $\mathrm{CHF}$ - including readmission rates, lengths of stay, mortality, and other untoward outcomes. ${ }^{3-9}$ The 
recent availability of point-of-care BNP assays and therapeutic BNP (nesiritide) has stimulated a great deal of contemporary research. Several reviews have recently been undertaken in pediatrics that acknowledge that perturbations of the natriuretic hormone system are common in the settings of critical illness and congenital heart disease (CHD) but assert that further investigation is needed before this measure is of practical utility in these populations. ${ }^{10-16}$

As a therapeutic agent, human recombinant BNP (hrBNP) has been used to treat adults and children with decompensated CHF, demonstrating some improvements in cardiac performance. ${ }^{17-19}$ While garnering early enthusiasm, several studies subsequent to Food and Drug Administration approval have questioned the safety of therapeutic hrBNP, noting possible increased risks of renal dysfunction and mortality. ${ }^{20-22}$ A prospective study of hrBNP in adults is expected to be completed in 2010 and should inform current safety concerns. ${ }^{23}$

While extrapolations might be reasonably made from adult CHF populations to children with anatomically normal but failing hearts, less is known about the utility of BNP in the perioperative management of children undergoing repair of CHD. Because of the numerous congenital cardiac defects, intracardiac shunting, complex pressurevolume loading, as well as the marked physiologic elevation in the neonatal period, BNP may well have conditional validity and variable cutoffs as a marker for cardiac function in specific types of CHD. ${ }^{8,9,11,24-29}$

The literature regarding BNP in CHD has largely been descriptive, demonstrating broad correlations to severity of illness and adverse clinical outcomes, and also suggesting possible cutoff points for risk stratification. However, there remains little data to suggest how measuring BNP levels could guide perioperative decision making or therapy in any practical sense. ${ }^{13,14,24,30-34}$ Therefore, we sought to look at similar perioperative CHD BNP data from a different vantage point. Beyond further characterization of perioperative BNP levels generally, our efforts were aimed at identifying circumstances where BNP levels appeared disproportionately low relative to the clinical severity of CHF compared with other CHD patients. Such subpopulations might theoretically benefit from administration of hrBNP based on a theragnostic rationale, possibly giving $\mathrm{BNP}$ a more practical role in the perioperative management of CHD. ${ }^{35}$

\section{Methods}

\section{Study Design}

This study was approved by an institutional review board (IRB) and was conducted at Rady Children's Hospital in San Diego, California. All the subjects' legal guardians signed a written consent. Where possible, developmentally appropriate subjects signed a written assent.

This prospective observational study enrolled subjects from birth through 22 years of age with any congenital heart lesion undergoing open surgical repair. For a normative control group, a convenience blood sample was obtained and BNP measured in children without cardiopulmonary disease who were undergoing sedation or general anesthesia for minor procedures or imaging. For a surgical stress control group, BNP was measured before and after prolonged, intensive surgeries in children without cardiopulmonary disease. Patients, surgeons, and anesthesiologists were blinded to the measured BNP values of all the subjects and the controls. Operative variables were obtained, including cardiac lesion(s), surgical correction(s), and durations of surgery, cardiopulmonary bypass, and aortic cross-clamp. These subjects were comanaged postoperatively in two separate care units - the Pediatric Intensive Care Unit (PICU) and the Neonatal Intensive Care Unit (NICU) — based on age. Cardiology and cardiothoracic surgical teams were the same, but intensivists and support staff differed in these ICUs.

Blood samples were analyzed for BNP using the Triage Meter (Biosite, Inc., San Diego, CA, USA) in accordance with the product insert. In the main study group, BNP was measured at the following times: preoperatively, on arrival to the intensive care unit postoperatively, every 6 hours for 24 hours, daily through postoperative day number 5, before and after specified events (e.g., extubation, extra-corporeal membrane oxygenation (ECMO) initiation, chest closure, operative revisions), and upon exiting the ICU or becoming non-ICU status. Samples were no longer obtained after the patients left the ICU, even if this occurred before postoperative day number 5 . For comparative and statistical purposes, the following isolated and composite BNP measures were established for each patient: preoperative $\mathrm{BNP}$, peak BNP postoperatively, 24-hour average BNP postoperatively, and maximum positive change in BNP over 6 hours during the first postoperative day. 
Clinical data were obtained with each postoperative BNP sample, including urine output, central venous pressure (CVP), clinical perfusion assessment by nursing, and cardiovascular medications with doses. Composite scores were created from serial data obtained on postoperative day 1 . These composite postoperative outcome measures included daily averages of clinical perfusion, inotropic support, and CVP. Perfusion was scored 0-4 points for each of three aspects routinely charted by the bedside nurse in all cardiac patientscapillary refill, peripheral pulses, and extremity temperature-for a total range of $0-12$. An inotropic score with a potential range of $0-8$ was devised based on the number of four agents commonly used and on dose ranges reflective of local titration practice patterns ( 0 points if inotropic agent absent; +1 point if dopamine $<5 \mathrm{mcg} / \mathrm{kg} / \mathrm{m}$, epinephrine $\quad<0.05 \mathrm{mcg} / \mathrm{kg} / \mathrm{m}$, dobutamine $<5 \mathrm{mcg} / \mathrm{kg} / \mathrm{m}$, or milrinone $\leq 1 \mathrm{mcg} / \mathrm{kg} / \mathrm{m} ;+2$ points if dopamine $\geq 5 \mathrm{mcg} / \mathrm{kg} / \mathrm{m}$, epinephrine $\geq 0.05 \mathrm{mcg} / \mathrm{kg} / \mathrm{m}$, dobutamine $\geq 5 \mathrm{mcg} / \mathrm{kg} / \mathrm{m}$, milrinone $>1 \mathrm{mcg} / \mathrm{kg} / \mathrm{m}$ ). All composite scores described herein were devised strictly for analysis in this study. Low cardiac output syndrome (LCOS) was prospectively defined as 2 or more of the following clinical signs or symptomsspecifically oliguria $(<0.5 \mathrm{~mL} / \mathrm{kg} /$ hour $)$, perfusion impairment (perfusion score $<5$ ), or hemodynamic impairment (CVP $>15 \mathrm{~mm} \mathrm{Hg}$ )—without consideration of laboratory findings. ${ }^{36}$ Finally, open chest status, as well as lengths of mechanical ventilation, critical care status, and hospitalization, were recorded.

Between November 2003 and May 2005, a total of 221 patients were enrolled-102 normative controls, 13 surgical stress controls, and 106 congenital heart lesion repairs. One of the CHD patients was transferred to another ICU after surgery and was unable to be followed up.

\section{Statistical Analysis}

This sample was analyzed as a group and by subsets based on age, care unit, cardiac lesion, surgical repair, and final cardiac physiology. Distributions and time-vs.-BNP curves were plotted to characterize aggregate and subset samples. The distributions of BNP values were consistently asymmetric (medians lower than means) and CHD-specific subsets of the sample were relatively small. Therefore, nonparametric statistical tests were generally preferred, and data were not transformed except for graphical display. The Mann-Whitney rank-sum test was used for two sample comparisons and Wilcoxon's signed-rank test for matched pairs. Fisher's exact test was used for 2-by-2 nominal comparisons of groups. Specific associations between BNP measures, operative variables, and postoperative outcomes were prospectively sought, and where additional patterns emerged, these were explored on a post hoc basis. Corrections of $P$ values were not made for multiple simultaneous tests, given the exploratory nature of the post hoc analyses. For BNP assay results outside the range of the $\mathrm{BNP}$ meter, the range limit was used for statistical calculations.

\section{Results}

Normative BNP levels obtained from 102 subjects from adjusted gestational age of 30 weeks through 22 years sorted clearly into two populations: neonates and preterm infants $<44$ weeks adjusted gestational age, and infants $>4$ weeks of age and older children. The difference in medians between the neonates plus preterm infants vs. all the older children was 27 vs. $7 \mathrm{pg} / \mathrm{mL}$, respectively $(P<0.001)$. The BNP levels in non-neonatal children are low and narrowly distributed (median of $6.9 \mathrm{pg} / \mathrm{mL}$, interquartile range of $5-13.3 \mathrm{pg} / \mathrm{mL}$, and a maximum of $52.1 \mathrm{pg} / \mathrm{mL}$ ).

Thirteen surgical stress controls ages $0.4-17$ years (median 9.4 years) underwent prolonged invasive surgeries (the majority were anteriorposterior spinal fusions) with a median intraoperative duration of 3.8 hours (range 2.3-5.3 hours) and volume administration of $30 \mathrm{~mL} / \mathrm{kg}$ (range $12-92 \mathrm{~mL} / \mathrm{kg}$ ). Median preoperative and postoperative BNP were both $6.9 \mathrm{pg} / \mathrm{mL}$, with maximal changes of +1.3 and $-6.6 \mathrm{pg} / \mathrm{mL}$. Changes did not correlate to surgical duration or administration of volume.

Serial BNP measurements were obtained from 105 children undergoing repair of CHD. Table 1 summarizes the characteristics of this surgical cohort. The majority of the patients were cared for in the PICU $(\mathrm{n}=91)$ and a minority in the NICU $(n=14)$. Because of the striking difference in neonatal BNP levels (not unlike the neonatal controls), statistical analyses were segregated by neonatal vs. non-neonatal status, except when comparing these two groups.

Median preoperative and postoperative BNP levels in non-neonatal CHD were 22 and $41 \mathrm{pg} / \mathrm{mL}$ (median change of $+19 \mathrm{pg} / \mathrm{mL}, P<$ 0.001), and neonatal CHD repairs demonstrated respective levels of 2370 and $2140 \mathrm{pg} / \mathrm{mL}$ (median change of $-230 \mathrm{pg} / \mathrm{mL}, P=0.9$ ). Age was plotted 
Table 1. Descriptive Statistics of Congenital Heart Disease Subjects

\begin{tabular}{|c|c|}
\hline Demographics & Values \\
\hline Age, in years, median (range) & $1.0(0-17)$ \\
\hline Weight, in kg, median (range) & $8.4(1.9-85)$ \\
\hline Male : female, $n(\%)$ & $64: 41(61: 39)$ \\
\hline $\begin{array}{l}\text { Pediatric : neonatal intensive care } \\
\text { unit, } \mathrm{n}(\%)\end{array}$ & $91: 14(87: 13)$ \\
\hline Lesions, n (\%) & $105(100)$ \\
\hline Ventricular septal defect (VSD) & $13(12)$ \\
\hline Tetralogy of Fallot (TOF) & $12(11)$ \\
\hline $\begin{array}{l}\text { Hypoplastic left heart syndrome } \\
\text { (HLHS) }\end{array}$ & $11(11)$ \\
\hline Atrio-ventricular canal (AVC) & $10(9.5)$ \\
\hline Complex single ventricle (CSV) & $8(7.6)$ \\
\hline Atrial septal defect (ASD) & $8(7.6)$ \\
\hline $\begin{array}{l}\text { Transposition of the great arteries } \\
\text { (TGA) }\end{array}$ & $6(5.7)$ \\
\hline Double-outlet right ventricle (DORV) & $5(4.8)$ \\
\hline Tetrology of Fallot, repaired (TOF-R) & $5(4.8)$ \\
\hline Pulmonary atresia + VSD (PA-VSD) & $5(4.8)$ \\
\hline $\begin{array}{l}\text { PA + intact ventricular septum } \\
\text { (PA-IVS) }\end{array}$ & $3(2.9)$ \\
\hline $\begin{array}{l}\text { Atrio-ventricular canal, unbalanced } \\
\text { (AVC-UN) }\end{array}$ & $3(2.9)$ \\
\hline Tricuspid atresia (TA) & $3(2.9)$ \\
\hline $\begin{array}{l}\text { Others (if fewer than } 3 \text { of a lesion } \\
\text { type) }\end{array}$ & $14(13)$ \\
\hline Repairs, n (\%) & $105(100)$ \\
\hline Complete repair $(\mathrm{CR})$ & $58(55)$ \\
\hline $\begin{array}{l}\text { Total-cavo-pulmonary anastomosis } \\
\text { (T-CPA), all fenestrated Fontans }\end{array}$ & $16(15)$ \\
\hline $\begin{array}{l}\text { Superior-CPA (S-CPA), mainly } \\
\text { bidirectional Glenns }\end{array}$ & $7(6.7)$ \\
\hline $\begin{array}{l}\text { Stage-1 palliation (S1P), mainly } \\
\text { Norwoods }\end{array}$ & $7(6.7)$ \\
\hline Arterial switch & $6(5.7)$ \\
\hline $\begin{array}{l}\text { Right ventricular outflow tract } \\
\text { revision (RVOT-R) }\end{array}$ & $5(4.8)$ \\
\hline Valve repair / replacement & $4(3.8)$ \\
\hline $\begin{array}{l}\text { Pulmonary arterioplasty and } \\
\text { BT-shunt (PAP-BTS) }\end{array}$ & $3(2.9)$ \\
\hline \multicolumn{2}{|l|}{ Outcomes } \\
\hline $\begin{array}{l}\text { Length of surgery, in minutes, } \\
\text { median (range) }\end{array}$ & $248(114-807)$ \\
\hline $\begin{array}{l}\text { Length of bypass, in minutes, } \\
\text { median (range) }\end{array}$ & $119(0-346)$ \\
\hline $\begin{array}{l}\text { Length of cross-clamp, in minutes, } \\
\text { median (range) }\end{array}$ & $51(0-164)$ \\
\hline $\begin{array}{l}\text { Length of ventilator, in days, median } \\
\text { (range) }\end{array}$ & $1.35(0.5-59)$ \\
\hline $\begin{array}{l}\text { Length of intensive Care, in days, } \\
\text { median (range) }\end{array}$ & $2(1-59)$ \\
\hline $\begin{array}{l}\text { Length of hospitalization, in days, } \\
\text { median (range) }\end{array}$ & $5(2-64)$ \\
\hline Low cardiac output syndrome (\%) & $29(28)$ \\
\hline $\begin{array}{l}\text { Extra-corporeal membrane } \\
\text { oxygenation, } \mathrm{n}(\%)\end{array}$ & $3(2.9)$ \\
\hline Deaths, n (\%) & $3(2.9)$ \\
\hline
\end{tabular}

against 24-hour avg BNP in the CHD population, irrespective of cardiac lesion (Figure 1). BNP levels were higher in younger children, both within and between preoperative diagnostic categories, with a more marked and prolonged inverse agedependence in CHD patients than in controls.
Of the composite BNP scores devised, the postoperative 24-hour average BNP (24-hour avg BNP) had the highest overall correlation to postoperative outcomes and was therefore the preferred BNP measure for further analysis (Table 2). The weakest correlations were between postoperative BNP and intraoperative variables, although length of surgery was significant where the durations of cardiopulmonary bypass and aortic crossclamp were not. The postoperative peak BNP and 24-hour avg BNP both correlated significantly with all postoperative outcomes noted in Table 2, most notably, durations of open chest, ventilation, ICU stay, and hospitalization $(\mathrm{r}=0.51-0.65$, all $P<0.001)$. Preoperative BNP correlated with 24-hour avg BNP ( $\mathrm{r}=0.64, P<0.001)$, but was a weak predictor of intraoperative and postoperative measures ( $\mathrm{r}$ all $<0.31$, where significant).

Neonates and non non-neonates demonstrated significantly different BNP levels at all points in the time measured (Figure 2). The highest postoperative BNP occurred during postoperative day 1 in $92 \%$ of the patients, but the distribution was generally a right-skewed curve, with the mode occurring at 12 hours in $48 \%$ of the non-neonates and at 6 hours in $62 \%$ of the neonates (difference in time to peak $P<0.001$ ). After postoperative day 1 , the neonates most commonly demonstrated BNP levels lower than their preoperative levels-a pattern opposite to the non-neonates. Peak and 24-hour avg BNP were significantly higher in the non-neonatal CHD repairs with longer ICU and hospital stays. For the entire sample, mean BNP levels tended to be approximately twice the median value, and the peak BNP on postoperative day 1 was roughly twice the postoperative 24-hour average.

The median increase in BNP from preoperative BNP to postoperative 24-hour avg $\mathrm{BNP}$ in the non-neonatal populations was $251 \mathrm{pg} / \mathrm{mL}(P<$ 0.001). Corresponding BNP levels in the neonatal CHD population were substantially higher $(>1000 \mathrm{pg} / \mathrm{mL}$ difference, $P<0.001)$. The majority of BNP measurements that were in excess of the assay's upper limit ( $>5000 \mathrm{pg} / \mathrm{mL})$ occurred in the postoperative neonates with $\mathrm{CHD}$, decreasing sensitivity to any upward trends in this subset. Only 1 of $92(1 \%)$ non-neonates had a peak BNP that was lower than the preoperative BNP (72 vs. $101 \mathrm{pg} / \mathrm{mL}$, diagnosis of pulmonary atresia with ventriculoseptal defect). However, 2 of 10 (20\%) neonates had a preoperative $\mathrm{BNP}$ greater than their postoperative peak.

Patterns of perioperative BNP expression had great variability between and within CHD lesions 


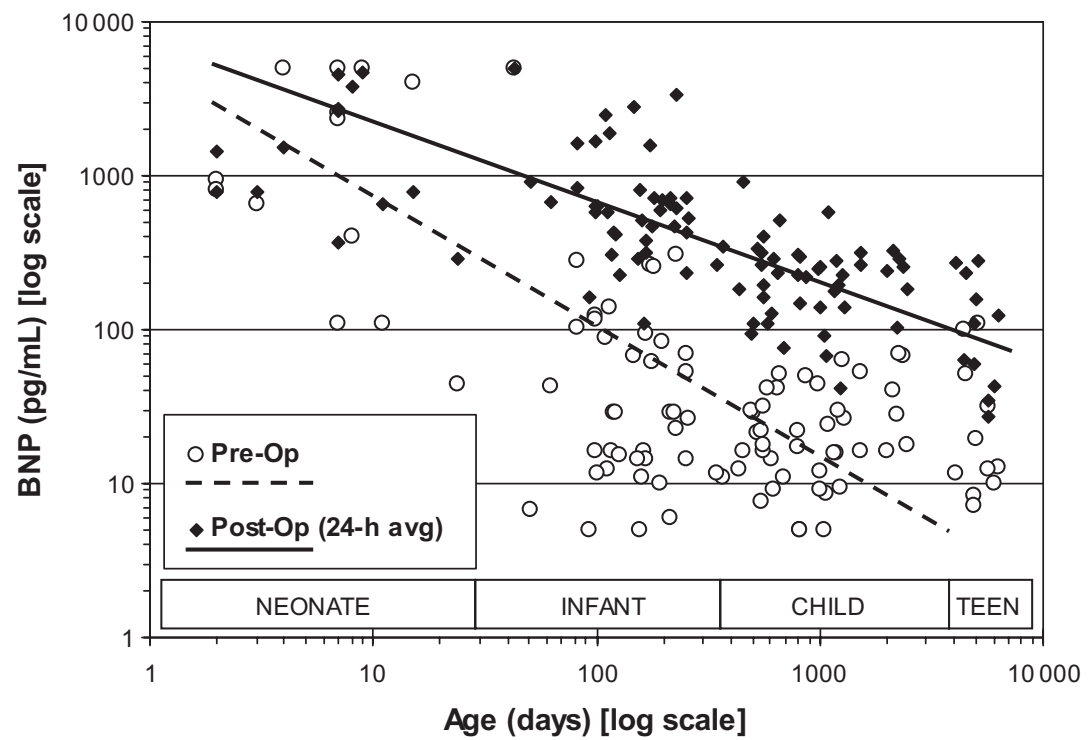

Figure 1. Preoperative and postoperative 24-hour average B-type natriuretic peptide (BNP) levels vs. patient age in congenital heart disease (CHD) patients. Children of younger age demonstrate higher BNP levels. Distinct from normative controls, this age-dependence in CHD persists years into childhood, and it appears to be most pronounced in postoperative BNP levels. When analyzed within different preoperative CHD diagnostic categories, this trend persists in 10 of 13 categories preoperatively and 13 of 13 postoperatively.

Table 2. Significant Correlations between B-Type Natriuretic Peptide Measures and Other Clinical Measures in NonNeonatal Congenital Heart Disease Subjects

\begin{tabular}{|c|c|c|c|c|}
\hline \multirow{2}{*}{$\begin{array}{l}\text { B-Type Natriuretic Peptide (BNP) } \\
\text { Non-Neonatal Population (n) }\end{array}$} & \multirow{2}{*}{$\frac{\text { Pre-Op (r) }}{\text { All (92) }}$} & \multicolumn{3}{|c|}{ Postoperative 24-hour Average (r) } \\
\hline & & All (92) & Biventricular (66) & Fontan (16) \\
\hline Length of aortic cross-clamp & - & - & - & - \\
\hline Length of cardiopulmonary bypass & - & - & - & - \\
\hline Length of surgery & $0.21^{*}$ & $0.28^{\star \star}$ & $0.23^{*}$ & - \\
\hline POD 1 urine output & - & - & - & - \\
\hline POD 1 perfusion score impairment & - & $0.28^{*}$ & $0.37^{\star \star}$ & - \\
\hline POD 1 central venous pressure & - & $0.27^{\star \star}$ & $0.38^{\star \star \star}$ & - \\
\hline POD 1 inotropic support score & $0.26^{\star}$ & $0.33^{\star \star *}$ & $0.46^{\star \star *}$ & - \\
\hline Length of chest open & - & $0.61^{* \star *}$ & $0.55^{\star \star *}$ & - \\
\hline Length of ventilation & $0.22^{*}$ & $0.51^{* * *}$ & $0.54^{\star \star *}$ & - \\
\hline Length of intensive care & $0.29^{* *}$ & $0.53^{\star * *}$ & $0.53^{\star * *}$ & $0.52^{*}$ \\
\hline Length of hospitalization & $0.31^{\star *}$ & $0.65^{\star \star \star}$ & $0.52^{\star \star *}$ & $0.51^{\star}$ \\
\hline Discharge diuretic dose & - & $0.33^{\star \star \star}$ & $0.26^{\star}$ & - \\
\hline Discharge ACE inhibitor dose & - & $0.20^{*}$ & $0.32^{*}$ & - \\
\hline
\end{tabular}

${ }^{\star} P<0.04 ;{ }^{* *} P<0.01 ;{ }^{* \star \star} P<0.001$.

$\mathrm{POD}$, postoperative day; ACE, angiotensin-converting enzyme.

(Figure 3), and BNP receiver-operator characteristic (ROC) curves were generally of weak discriminatory performance in our sample. The area under the curve (AUC) for the 24-hour avg BNP to detect LCOS was 0.61 in aggregate, 0.77 in neonates, and 0.56 in non-neonates.

Lesion-specific subsets were generally too small to perform meaningful statistical analyses. When aggregated into larger subsample categories based on stage of univentricular palliation vs. complete biventricular repairs (Figure 4), univentricular patients demonstrated a sequential decrease in BNP levels at each stage. Median postoperative 24-hour avg BNP for univentricular patients-Stage 1 Palliations, bidirectional Glenn anastamoses, and fenestrated fontanswere, respectively, 778, 415, and $150 \mathrm{pg} / \mathrm{mL}$, whereas the biventricular CHD repairs had a median postoperative 24-hour avg BNP of $318 \mathrm{pg} / \mathrm{mL}$.

A post hoc comparison was made between the Fontans and the non-neonatal biventricular sub- 


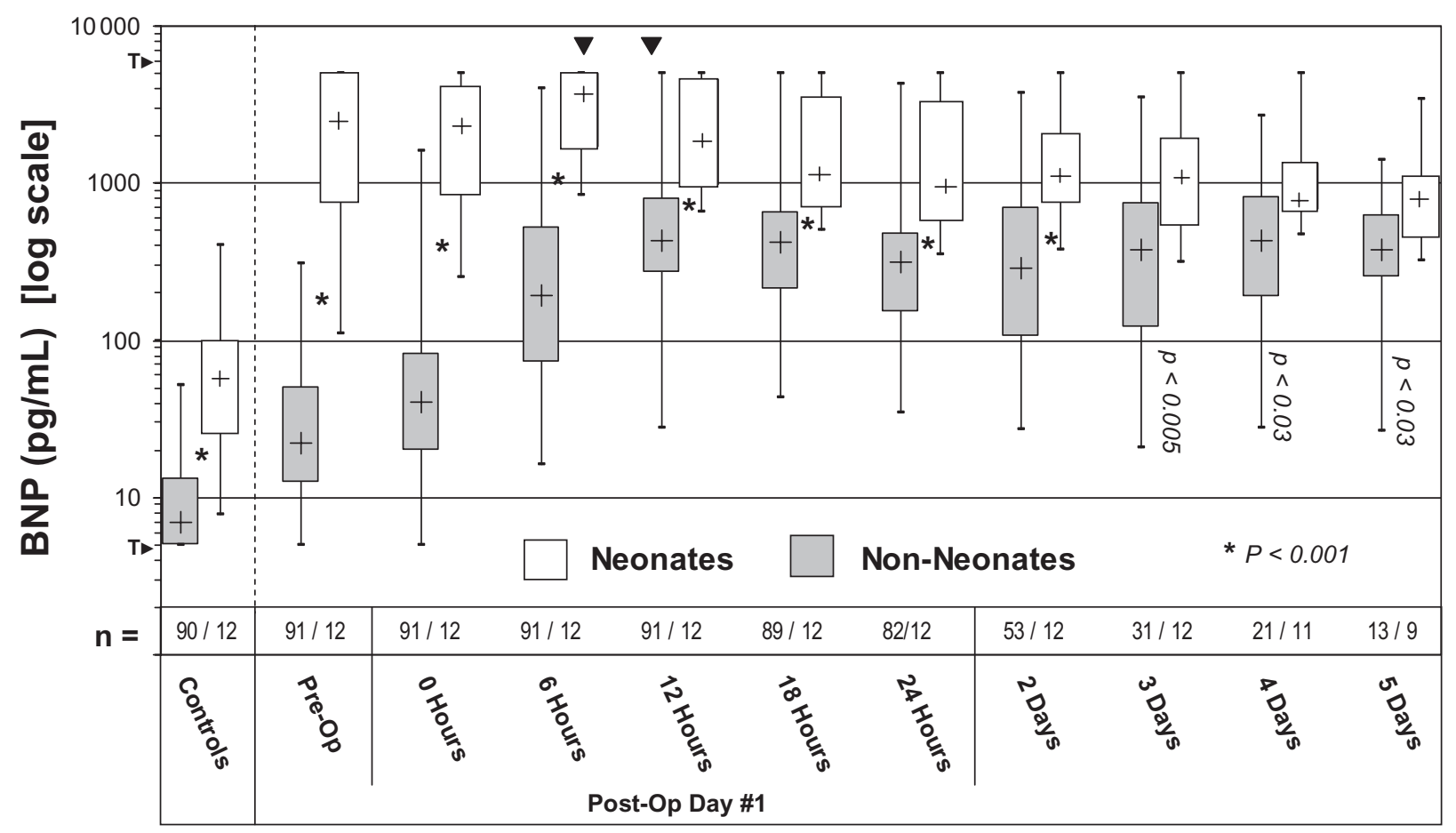

Figure 2. B-type natriuretic peptide (BNP) values across time: neonatal vs. non-neonatal congenital heart disease repairs. Neonatal and non-neonatal BNP values were distinct, both in timing of the peak and magnitude at each time point $(P$ values all significant). In non-neonates, BNP levels were consistently higher in children with longer lengths of ventilation, intensive care unit (ICU) stay, and hospitalization. Later time points partly reflect patient attrition from the ICU and should not be misconstrued to represent typical individual curves, which generally demonstrated gradual reduction in BNP after the peak on postoperative day 1 . The highest postoperative BNP occurred on postoperative day 1 in $92 \%$ of the patients, and the distribution was somewhat right-skewed with the mode (dark triangles) occurring at 12 hours in the pediatric ICU (48\% of patients) and at 6 hours (62\% of patients) in the neonatal ICU. This difference in time to peak was significant $(P<0.001)$. The two T's on the y-axis designate the upper and lower thresholds of the BNP assay.

jects (Table 3). Compared with the biventricular repairs, the Fontans demonstrated similar demographics but numerous measures of higher clinical acuity throughout the perioperative sequenceincluding higher doses of cardiovascular medications at admission and discharge, longer surgical time, higher inotropic requirements postoperatively, longer length of intensive care and hospitalization, and increased incidence of LCOS. The Fontan palliations demonstrated lower perioperative BNP measures than biventricular repairsincluding preoperative BNP (16 vs. $23 \mathrm{pg} / \mathrm{mL}, P=$ 0.09), peak BNP (266 vs. $592 \mathrm{pg} / \mathrm{mL}, P<0.001$ ), maximal rate of rise $(24$ vs. $60 \mathrm{pg} / \mathrm{mL} /$ hour, $P=$ 0.001 ), and 24 -hour postoperative average (150 vs. $306 \mathrm{pg} / \mathrm{mL}, P<0.001)$. The non-neonatal CHD sample demonstrated a positive and significant correlation between the postoperative 24-hour avg $\mathrm{BNP}$ and numerous clinical measures of acuity (Table 2), and while the biventricular CHD correlations were generally stronger, the Fontan sub- group demonstrated weakly negative, statistically nonsignificant correlations to most of these same measures.

To assess the impact of cardiopulmonary bypass on very high BNP levels, the patients with preoperative $\mathrm{BNP}>1000 \mathrm{pg} / \mathrm{mL}$ had two additional intraoperative BNP samples: $\sim 5$ minutes after beginning cardiopulmonary bypass and $\sim 5$ minutes prior to unclamping the aorta. Of the 7 subjects with preoperative BNP levels $>1000 \mathrm{pg} / \mathrm{mL}$ (all neonates), 5 were captured for this analysis. BNP levels uniformly dropped to a nadir at the end of aortic cross-clamp, rising again postoperatively to near-preoperative levels (Figure 5). The mean difference in BNP between preoperative $(3926 \mathrm{pg} / \mathrm{mL})$ and end of the crossclamp $(822 \mathrm{pg} / \mathrm{mL})$ was $3104 \mathrm{pg} / \mathrm{mL}(P<0.07)$.

Three subjects died, including one neonate (hypoplastic left heart syndrome [HLHS] undergoing Norwood palliation) and two non-neonates (HLHS undergoing a bidirectional Glenn proce- 


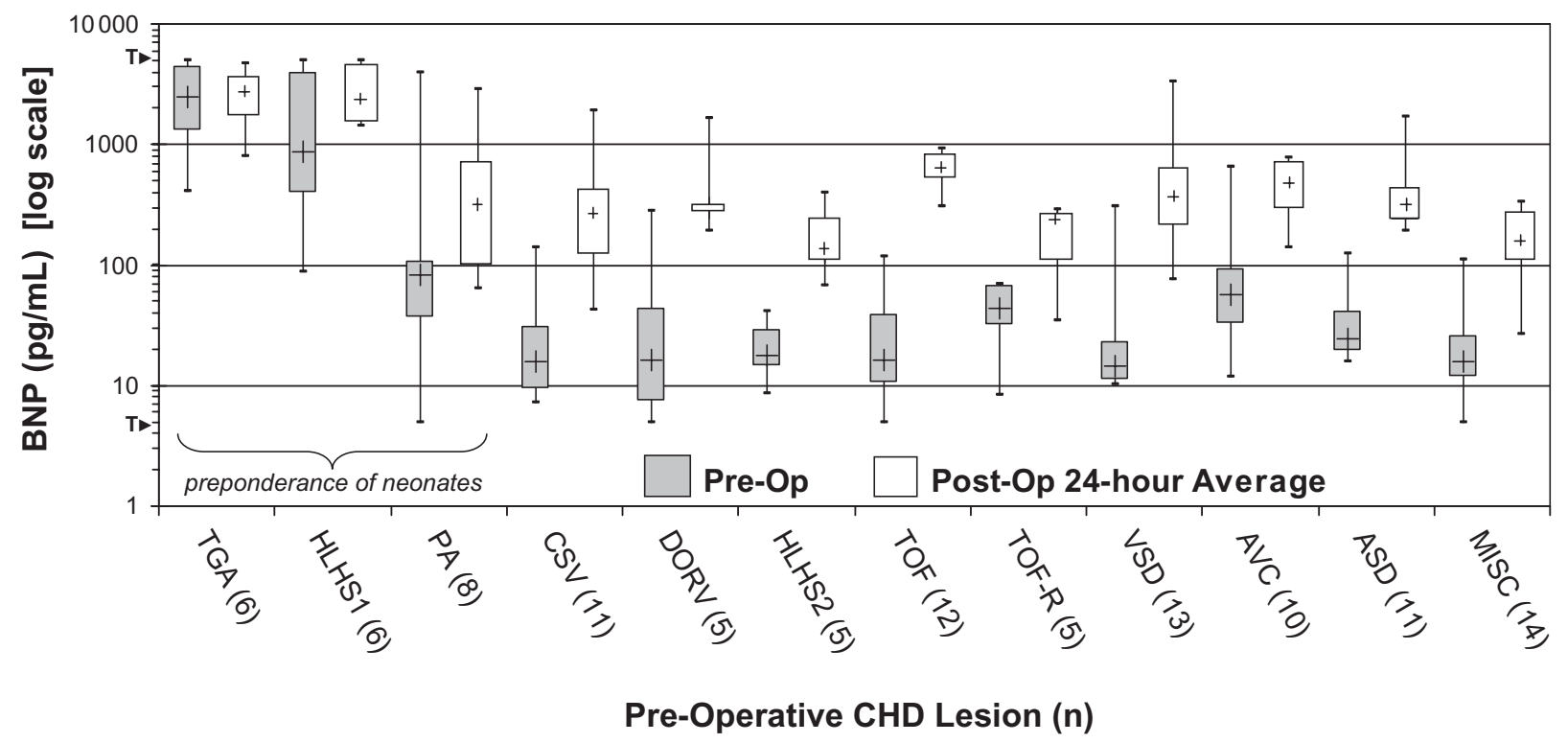

Figure 3. Preoperative B-type natriuretic peptide (BNP) and postoperative 24-hour average BNP in selected congenital heart disease lesions. Significant interindividual, interlesional, and age-dependent variability exists in BNP expression. TGA, transposition of the great arteries; HLHS1/2, hypoplastic left heart syndrome, Stage 1/2; PA, pulmonary atresia; CSV, complex single ventricle; DORV, double outlet right ventricle; TOF(-R), tetrology of Fallot (repaired); VSD, ventricular septal defect; AVC, atrio-ventricular canal; ASD, atrial septal defect; MISC, miscellaneous lesions (for which $\mathrm{n}<5$ for that lesion type). The two T's on the y-axis designate the upper and lower thresholds of the BNP assay.

dure, and a pulmonary atresia-ventricular septal defect undergoing an attempted biventricular repair). Within the non-neonatal cohort, the two nonsurvivors demonstrated preoperative BNP levels in the $83 \mathrm{rd}-88$ th percentile $(67-88 \mathrm{pg} / \mathrm{mL})$ and postoperative 24-hour average BNP in the 98-99th percentile $(2492-2831 \mathrm{pg} / \mathrm{mL})$. In contrast, the neonatal nonsurvivor's BNP was $<50$ th percentile both preoperatively and postoperatively. If a composite measure of "adverse outcomes" is defined as death, cardiac arrest, or ICU length of stay $>28 d$, a group of 5 non-neonatal patients were identified that demonstrated a preoperative BNP ROC AUC of 0.83 (BNP of $>64 \mathrm{pg} / \mathrm{mL}$ yields $80 \%$ sensitivity and $85 \%$ specificity), while the 24-hour avg BNP ROC AUC is 0.96 (24-hour avg BNP of $>721 \mathrm{pg} / \mathrm{mL}$ yields $80 \%$ sensitivity and $92 \%$ specificity).

\section{Discussion}

Normative pediatric BNP levels in children are lower and more narrowly distributed than in adults - with the notable exception of newborns and preterm infants who may exhibit high, widely distributed BNP levels during their circulatory transition. ${ }^{37}$ Our data suggest a nadir in the first year of life, after which, a gradual rise in BNP appears to take place. No straightforward surgical control group exists for CHD repairs, but in an effort to compare with some kind of relatable surgical stress, we selected a small sample of noncardiac surgeries expected to be several hours in duration with significant intraoperative blood loss and volume resuscitation. These controls demonstrated normal preoperative and postoperative BNP levels unaffected by intraoperative variables. In contrast, the non-neonatal CHD patients' postoperative BNP levels rose significantly by several orders of magnitude. This suggests that rising BNP levels in the CHD repairs are not likely relatable to nonspecific surgical stresses, anesthetic exposure, or routine intraoperative volume management for blood loss.

The vast majority of preoperative BNP levels in non-neonatal CHD were within the commonly accepted normative range for this assay $(<100 \mathrm{pg} /$ $\mathrm{mL}$ ), likely reflecting a state of compensated CHF. Composite and isolated postoperative BNP levels correlated with numerous aspects of $\mathrm{CHF}$ in CHD repairs-including the timing and severity of LCOS, duration of ICU support, discharge medication doses, and a composite of adverse outcomes. Because BNP usually peaked on postoperative day 1 , and because the time to peak varied, averaging BNP values over the first 24 hours to 


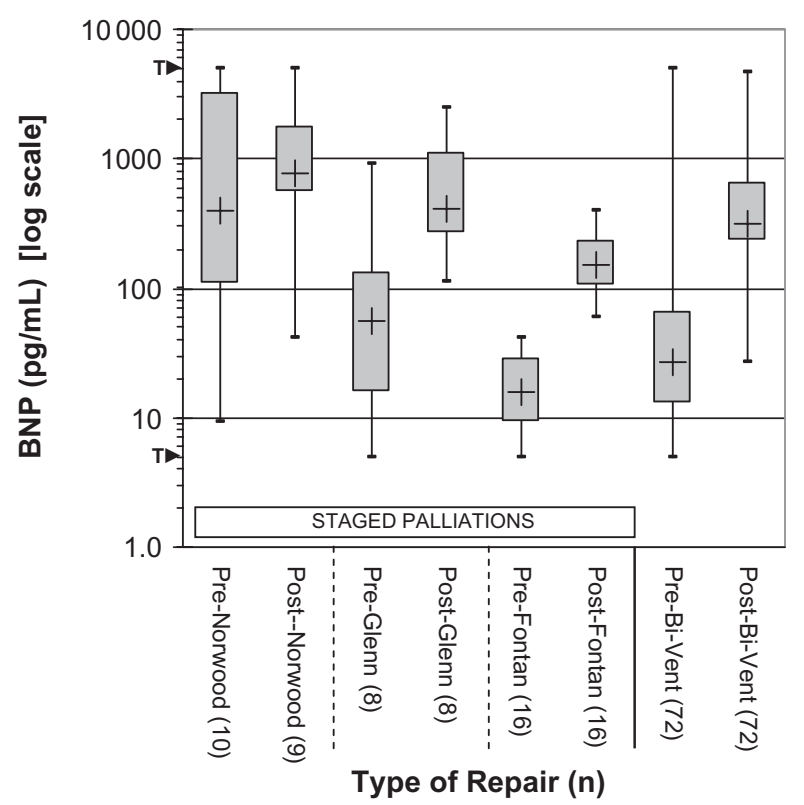

Figure 4. Preoperative and 24-hour average postoperative B-type natriuretic peptide (BNP) levels in staged univentricular palliations vs. complete biventricular repairs. Early postoperative BNP expression is higher in all groups of congenital heart disease repairs shown. In univentricular repairs, BNP trends downward with advancing stage and age. Pre, preoperative; Post, postoperative; Norwood, predominantly Norwoods plus similar stage-1 palliations; Glenn, predominantly bidirectional Glenns plus similar superior cavopulmonary anastamoses; Fontan, fenestrated Fontans; Bi-Vent, complete biventricular repairs. The two T's on the $y$-axis designate the upper and lower thresholds of the BNP assay.

estimate an AUC resulted in the composite measure that best correlated to clinical measuresand was the measure felt to be most reflective of overall physiologic BNP response. BNP levels appeared to behave as one might expect to common perioperative maneuvers-rising transiently after sternal closure and after discontinuing positive pressure ventilation (data not shown)and generally trended down after a peak on postoperative day 1 as the patients convalesced.

When assessed in aggregate or by CHD lesion, BNP levels fell logarithmically with age, both preoperatively and postoperatively (Figure 1) - in contrast to the normative controls that trended upward after the neonatal period. In contrast to neonatal controls, this inverse age-dependence of BNP levels in CHD persisted years into life-not merely during the period of transitional circulation. While $\mathrm{BNP}$ trends might be influenced by different cardiac lesions being repaired at different ages, when analyzed within a dozen different pre- operative diagnostic categories, this BNP-vs.-age relationship persisted universally in postoperative BNP and was re-demonstrated with preoperative BNP in the vast majority of categories.

Others have reported point-in-time cutoff values for $\mathrm{BNP}$ as a risk stratifier or predictor of outcomes in CHD, and similar analyses of our data are consistent with many of these findings. ${ }^{7-9,14,27-29,33,34}$ Therefore, we looked at our perioperative BNP data from a slightly different perspective-seeking situations where BNP levels and severity of illness appeared discordant. Two such populations stood out: Fontans in general and neonates intraoperatively.

In a small sample of non-neonatal CHD repairs, Ationu found that preoperative BNP was within normal limits and only trivially reduced intraoperatively at various stages during $\mathrm{CPB}^{38}$ much as our CHD and surgical control data show. However, since BNP is rapidly liberated and has a half-life of approximately 22 minutes, intraoperative reductions may not be apparent in patients with normal preoperative BNP concentrations. Therefore, we selected CHD subjects with preoperative BNP greater than $1000 \mathrm{pg} / \mathrm{mL}$ for additional intraoperative BNP sampling (only neonates had preoperative levels this high). While a small sample, all five cases demonstrated the same pattern: BNP levels dropped dramatically while on cardiopulmonary bypass and reached a nadir at the end of aortic cross-clamp. Possible mechanisms include dilution from the proportionally larger bypass circuit prime in neonates, exclusion of the ramped up BNP-producing myocardium from the circulating blood volume, increased elimination efficiency by ultrafiltration, or upregulated peripheral metabolism of BNP. These remarkably high levels of BNP preoperatively may be physiologic and adaptive in neonatal $\mathrm{CHD}$, and iatrogenic reductions intraoperatively could theoretically contribute to impaired physiologic homeostasis postoperatively.

In our comparison of biventricular repairs and Fontan palliations (Tables 2 and 3), the univentricular patients demonstrated higher clinical acuity yet significantly lower BNP measures-less than half the average amount of BNP on postoperative day 1 . The Fontan patients required more cardiac medication, had longer lengths of stay, were readmitted more often, and showed an almost 3-fold increase in LCOS (in spite of similar CBP run lengths). In stark contrast to biventricular CHD, the Fontan palliations paradoxically demonstrated weak inverse correlations between 
Table 3. Comparison of Perioperative Measures between Fontan Palliations and Non-Neonatal Complete Biventricular Congenital Heart Disease Repairs

\begin{tabular}{|c|c|c|c|}
\hline Type of Surgical Repair/Palliation & Complete (Biventricular) & Fontan (Univentricular) & $P$ \\
\hline \multicolumn{4}{|l|}{ Demographics } \\
\hline Sample Size $(n)$ & 66 & 16 & \\
\hline Age (in years, median/IQR) & $1.2(0.4-4.2)$ & $1.7(1.5-2.8)$ & - \\
\hline Weight (in kg, median/IQR) & $9.0(5.5-16)$ & $10.5(9.5-12.4)$ & - \\
\hline \multicolumn{4}{|l|}{ Admission measures (median/IQR) } \\
\hline Number of cardiovascular medications & $0.5(0-2)$ & $1(1-2)$ & - \\
\hline Furosemide/equivalent dose (mg/kg/d) & $0(0-1.2)$ & $0.3(0-1.2)$ & - \\
\hline Captopril/equivalent dose $(\mathrm{mg} / \mathrm{kg} / \mathrm{d})$ & $0(0-0)$ & $0.3(0.05-0.6)$ & $<0.001$ \\
\hline \multicolumn{4}{|l|}{ BNP measures (median/IQR) } \\
\hline BNP, preoperative (pg/mL) & $23(12-53)$ & $16(9-30)$ & 0.09 \\
\hline BNP, peak postoperative $(\mathrm{pg} / \mathrm{mL})$ & $592(432-1150)$ & $266(178-442)$ & $<0.001$ \\
\hline BNP, 24-h postoperative average ( $\mathrm{pg} / \mathrm{mL})$ & $306(226-604)$ & $150(102-244)$ & $<0.001$ \\
\hline BNP, maximum rate of increase $(\mathrm{pg} / \mathrm{mL} / \mathrm{h})$ & $60(31-108)$ & $24(19-49)$ & 0.001 \\
\hline \multicolumn{4}{|l|}{ Intraoperative measures (median/IQR) } \\
\hline Length of aortic cross-clamp (min) & $56(42-87)$ & $52(39-59)$ & - \\
\hline Length of cardiopulmonary bypass (min) & $119(88-160)$ & $119(105-139)$ & - \\
\hline Length of surgery (hours) & $3.8(2.9-4.7)$ & $4.8(4.2-5.8)$ & 0.001 \\
\hline \multicolumn{4}{|l|}{ Clinical post-op measures (median/lQR) } \\
\hline POD 1 central venous pressure $(\mathrm{mm} \mathrm{Hg})^{\star}$ & $9.8(7.8-13.2)$ & $13.5(11.5-15.3)$ & $<0.001$ \\
\hline POD 1 perfusion score impairment $(0-12)$ & $1.6(1.1-2.2)$ & $2.2(1.2-2.9)$ & - \\
\hline POD 1 inotropic support score $(0-8)$ & $2(1.2-2.4)$ & $2.4(1.8-2.8)$ & 0.04 \\
\hline POD 1 urine output $(\mathrm{mL} / \mathrm{kg} / \mathrm{hr})$ & $2.3(1.7-3.2)$ & $1.9(1.5-2.7)$ & - \\
\hline \multicolumn{4}{|l|}{ Duration post-op measures (median/IQR) } \\
\hline Length of ventilation (days) & $1.3(0.8-2.6)$ & $1.1(0.9-1.5)$ & - \\
\hline Length of intensive care (days) & $2.0(1-4)$ & $3.0(2-3.5)$ & 0.08 \\
\hline Length of hospitalization (days) & $4.5(3-7)$ & $6.0(5.5-7.5)$ & 0.01 \\
\hline \multicolumn{4}{|l|}{ Discharge measures (median/IQR) } \\
\hline Number of cardiovascular medications & $2(1-3)$ & $3(3-3)$ & 0.001 \\
\hline Furosemide/equivalent dose (mg/kg/day) & $2.6(1.3-3.0)$ & $2.9(2.6-3.1)$ & 0.09 \\
\hline Captopril/equivalent dose (mg/kg/day) & $0(0-0.5)$ & $0.7(0.5-1)$ & $<0.001$ \\
\hline \multicolumn{4}{|l|}{ Binary outcomes } \\
\hline Low cardiac output syndrome (n, \%) & $13(20)$ & $9(56)$ & $<0.01$ \\
\hline Open chest postoperatively (n, \%) & $4(6.1)$ & $0(0)$ & - \\
\hline Deaths $(n, \%)$ & $1(1.5)$ & $0(0)$ & - \\
\hline Readmission $<6$ weeks from discharge $(\mathrm{n}, \%)$ & $2(3.0)$ & $2(12)$ & - \\
\hline
\end{tabular}

${ }^{*}$ Represents pulmonary artery pressure for Fontan physiology.

BNP, B-type natriuretic peptide; IQR, interquartile range; POD, postoperative day.

BNP and both CVP as well as inotrope score. With only 6 bidirectional Glenn anastamoses, analyses of this univentricular stage were quite limited statistically, but in general, these patients demonstrated similar BNP measures but worse clinical outcomes than the biventricular repairsalso suggesting a degree of discord between BNP and outcomes in this univentricular population. These findings supplement previous reports by others citing progressively lower BNP expression in staged univentricular CHD repairs-perhaps because of isolated cavopulmonary failure or impaired perioperative expression of natriuretic peptides. ${ }^{24,26,28}$ These data also give us cause to consider whether BNP levels are mal-aligned with the clinical severity of CHF in these populations. While speculative, impairment of an otherwise adaptive BNP response in this population could conceivably contribute to the tendency of univentricular patients to require greater medical support and exhibit longer lengths of stay.
Measured BNP levels clearly reflect an equilibrium between many variables: production, degradation, endocytosis, excretion, and dilution. This can seriously confound the interpretation of BNP in perioperative CHD when many of these variables are not in a predictable steady state. Yet, with the exception of overt renal dysfunction, measured BNP levels appear to predominantly reflect production by the ventricular myocardium. ${ }^{39,40}$ However, while BNP correlates to clinical measures and predicts poor outcomes (similar to many biomarkers), it does not reveal much that is not already apparent to clinicians-that sicker patients require more support for a longer time and tend to do worse. Indeed, the existing literature on BNP in perioperative CHD does not meaningfully guide therapy, and BNP risk stratification has not translated into differing management algorithms. ${ }^{14,37,38,41-45}$

Questions clearly remain regarding the appropriateness and effectiveness of endogenous 


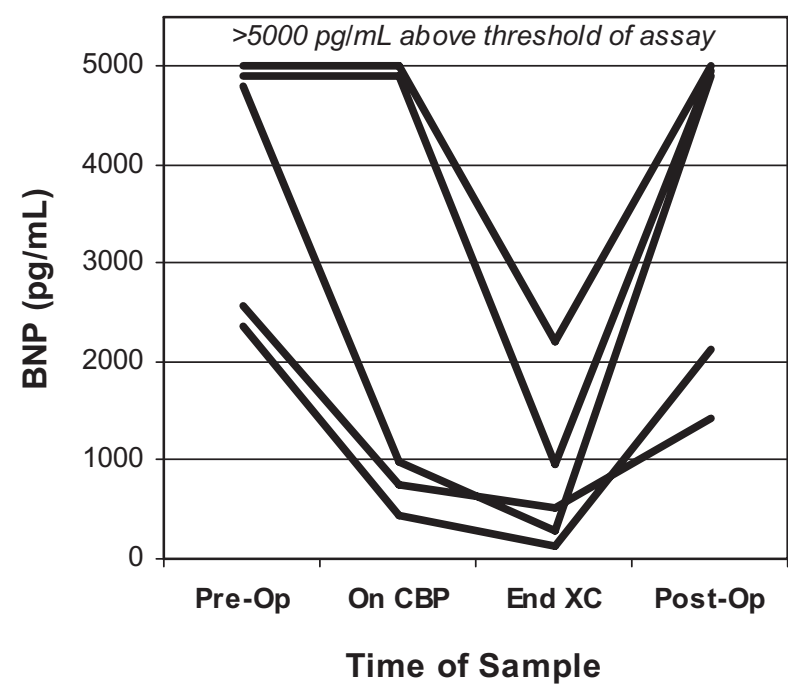

Figure 5. Intraoperative B-type natriuretic peptide (BNP) levels in five congenital heart disease repairs exhibiting markedly high preoperative BNP levels. In patients with very high levels of BNP preoperatively (all neonates), cardiopulmonary bypass and circulatory arrest consistently lowered serum BNP concentrations by thousands of $\mathrm{pg} / \mathrm{mL}$, which rose quickly postoperatively to near-preoperative levels. Pre-Op, preoperative; On CBP, $\sim 5$ minutes into cardiopulmonary bypass; End XC, $\sim 5$ minutes prior to unclamping aorta; Post-Op, upon arrival to the intensive care unit (ICU) postoperatively (hour 0 of BNP series in ICU).

BNP levels after CHD repair. In contrast to cardiomyopathies, CHD can have unique ventricular pressure-volume loading states because of parallel circulation, intracardiac shunting, single ventricle physiologies, ventricular reversals, and complex surgical reconfigurations. Univentricular CHD may have relatively less BNP-producing myocardium. Certainly, the myocardium is not able to effectively liberate BNP during asystole following cardioplegia. It may be that such aspects of CHD could alter the normal adaptive function of this important counter-regulatory signal, resulting in BNP responses that are inappropriately low or high relative to the clinical magnitude of heart failure.

The off-label use of hrBNP in children undergoing CHD repair has been undertaken-with retrospective analyses and case series suggesting improved surrogate endpoints and an absence of obvious complications. ${ }^{19,23,46-49}$ However, clear indications, proven efficacy, and convincing safety have not been demonstrated. Exogenous BNP has several theoretically desirable features in the care of postoperative CHD patients, including vasodilitation, diuresis, and lusitropy. Yet, metaanalyses of adult trials with hrBNP have raised concerns about increased renal dysfunction and mortality - so any therapeutic manipulations of the BNP axis ought not be applied indiscriminately without further guiding evidence. ${ }^{21,22}$ The prospect of perioperative BNP elevations insufficient for optimal adaptation would provide a tempting mechanistic rationale for considering exogenous BNP in targeted CHD populations. Because nesiritide is a recombinant form of a human protein naturally found highly concentrated in children with heart failure, the drug may prove to be a safe and effective therapy in situations of relative deficiency-in contrast to creating supraphysiologic levels beyond the expected adaptive response in cardiomyopathy.

While our data do not definitively identify states of relative BNP insufficiency, it will remain challenging to tease out such a condition given the enormous variability in BNP responses superimposed on the clinical complexity of perioperative CHD. In this confounded and heterogeneous clinical setting, a theragnostic approach may be productive-using a biomarker to identify which patients are most likely to benefit from a specific drug therapy. ${ }^{35}$ Therefore, we suggest that a rationale exists for further research into targeted administration of hrBNP in some circumstances encountered in the perioperative management of CHD. These include: patients undergoing cardiopulmonary bypass with very high BNP levels preoperatively (in an effort to replace any iatrogenic decrement in an adaptive hormone) and postoperatively to univentricular palliations (where our data show relatively low BNP levels compared with clinical acuity). Clinical trials assessing the safety and efficacy of hrBNP in such circumstances should be undertaken, and our data provides a starting point for mechanistically guided use in future research.

There are significant limitations to our data limiting generalizability. The heterogeneous sample unevenly distributed among numerous small CHD subsets makes our aggregate analyses difficult to extrapolate to individual CHD lesions. In particular, the NICU subjects were only enrolled in the last third of the study window after an IRB amendment, resulting in a particularly small neonatal subsample. There was also a paucity of hemi-Fontans, further limiting the kinds of univentricular subgroup analyses that could be made. As a matter of feasibility and convenience in this unfunded study, a perfusion score was devised based on routine nursing assessments, rather than formal core-vs.-peripheral tempera- 
ture differentials. Also, an inotropic score was devised that weighted low, moderate, and high dosing levels in a manner that was felt to reflect local titration patterns. Because it used collapsed dose ranges rather than linear conversions, it is presumably less sensitive than other tools. While neither of these scales devised for this study are validated measures, they did both correlate as expected with other objective measures of clinical acuity and with each other. Apart from urine output, renal function was not measured, but since impaired renal function can result in elevated BNP levels, this is a potential confounder. However, $\mathrm{BNP}$ and UO did not correlate positively or negatively on postoperative day 1 . Another limitation is the management of CHD by two different ICUs and intensivists groups within our institution, potentially introducing systematic differences in the assessment and management. However, the cardiothoracic surgeons and cardiologists were the same, and the strikingly higher levels of BNP in the neonatal population (controls and CHD) suggests that this group needs to be analyzed separately from older infants and children regardless. Because perioperative BNP levels in the NICU population were frequently above the upper limit of measurability, the upper range limit of the meter was used in calculations, likely blunting the sensitivity of this measure in our analyses. Future research including neonates should consider more accurate methods of measuring very high BNP, such as through dilutional techniques or alternative assays. Finally, corrections of $P$ values were not made for multiple simultaneous tests, given the exploratory nature of the post hoc analyses, so marginally significant values should be treated with caution.

\section{Conclusions}

BNP is a valid biomarker for CHF in the CHD population during the perioperative period. Levels correlate to clinical severity of heart failure, lengths of therapy, and adverse outcomes. Peak BNP levels most often occurred 6-12 hours postoperatively, mirroring the classic period of the LCOS. However, the clinical utility of BNP as a rapid point-of-care diagnostic assay is limited after CHD repair because of the highly variable responses between and within CHD lesions as well as age-dependency. Randomly obtained BNP levels will remain difficult to interpret without other points on the BNP-vs.-time curve of an individual patient. Despite having greater clinical acuity and resource utilization, Fontan palliations paradoxically exhibited lower BNP expression preoperatively and postoperatively compared with biventricular CHD. This pattern of potential BNP insufficiency, as well as others described here, suggest rational targets for investigating therapeutic administration of hrBNP perioperatively.

\section{Acknowledgments}

The authors would like to thank the extraordinary nurses, respiratory therapists, and perfusionists at Rady Children's Hospital in San Diego for the enthusiasm and dedication which made this project possible. Additionally, we express our gratitude to Biosite, Inc., for supporting this pediatric research by donating the BNP meter and assay materials.

There was no direct financial support of this research. Biosite, Inc., the maker of the Triage Meter used to measure BNP levels, provided the following nonmonetary support: loan of a BNP meter, BNP test cartridges, technical assistance with the meter, and in-servicing of research personnel. A contractual agreement was secured prior to patient enrollment to permit the authors to publish results, regardless of the findings.

Corresponding Author: Matthew F. Niedner, MD, Division of Pediatric Critical Care, University of Michigan, 1500 East Medical Center Drive, Ann Arbor, MI 48109, USA. Tel: 764-647-0742; Fax: 734-6475624; E-mail: mniedner@umich.edu

Conflict of Interest: None.

Accepted in final form: Fanuary 30, 2010.

\section{References}

1 Westerlind A, Wahlander H, Berggren $\mathrm{H}$, Lundberg PA, Holmgren D. Plasma levels of natriuretic peptide type $\mathrm{B}$ and $\mathrm{A}$ in children with heart disease with different types of cardiac load or systolic dysfunction. Clin Physiol Funct Imaging. 2008;28:277284.

2 Maisel A. B-type natriuretic peptide levels: a potential novel "white count" for congestive heart failure. f Card Fail. 2001;7:183-193.

3 Harrison A, Morrison LK, Krishnaswamy P, et al. B-type natriuretic peptide predicts future cardiac events in patients presenting to the emergency department with dyspnea. Ann Emerg Med. 2002;39:131-138.

4 Cheng V, Kazanagra R, Garcia A, et al. A rapid bedside test for B-type peptide predicts treatment outcomes in patients admitted for decompensated heart failure: a pilot study. $7 \mathrm{Am}$ Coll Cardiol. 2001;37:386-391. 
5 Berger R, Huelsman M, Strecker K, et al. B-type natriuretic peptide predicts sudden death in patients with chronic heart failure. Circulation. 2002;105: 2392-2397.

6 Price JF, Thomas AK, Grenier M, et al. B-type natriuretic peptide predicts adverse cardiovascular events in pediatric outpatients with chronic left ventricular systolic dysfunction. Circulation. 2006;114:10631069.

7 Tan LH, Jefferies JL, Liang JF, et al. Concentrations of brain natriuretic peptide in the plasma predicts outcomes of treatment of children with decompensated heart failure admitted to the intensive care unit. Cardiol Young. 2007;17:397406.

8 Hsu JH, Keller RL, Chikovani O, et al. B-type natriuretic peptide levels predict outcome after neonatal cardiac surgery. 7 Thorac Cardiovasc Surg. 2007;134:939-945.

9 Hsu JH, Oishi PE, Keller RL, et al. Perioperative B-type natriuretic peptide levels predict outcome after bidirectional cavopulmonary anastomosis and total cavopulmonary connection. 7 Thorac Cardiovasc Surg. 2008;135:746-753.

10 Costello JM, Goodman DM, Green TP. A review of the natriuretic hormone system's diagnostic and therapeutic potential in critically ill children. Pediatr Crit Care Med. 2006;7:308-318.

11 Oishi PE, Fineman JR. BNP for pediatrics-not quite ready for primetime. Pediatr Crit Care Med. 2006;7:388-389.

12 Davis GK, Bamforth F, Sarpal A, et al. B-type natriuretic peptide in pediatrics. Clin Biochem. 2006; 39:600-605.

13 Nir A, Nasser N. Clinical value of NT-ProBNP and BNP in pediatric cardiology. 7 Card Fail. 2005;11 (suppl):S76-S80.

14 Berry JG, Askovich B, Shaddy RE, Hawkins JA, Cowley CG. Prognostic value of B-type natriuretic peptide in surgical palliation of children with singleventricle congenital heart disease. Pediatr Cardiol. 2008;29:70-75.

15 Tobias JD, Lindblade CL, Schamberger MS. B-type natriuretic peptide monitoring in the pediatric ICU population. Paediatr Anaesth. 2007;17:793-799.

16 El-Khuffash A, Molloy EJ. Are B-type natriuretic peptide (BNP) and N-terminal-pro-BNP useful in neonates? Arch Dis Child Fetal Neonatal Ed. 2007; 92:F320-F324.

17 Maisel AS. Nesiritide: a new therapy for the treatment of heart failure. Cardiovasc Toxicol. 2003;3:3742.

18 Jefferies JL, Denfield SW, Price JF, et al. A prospective evaluation of nesiritide in the treatment of pediatric heart failure. Pediatr Cardiol. 2006;27:402-407.

19 Jefferies JL, Price JF, Denfield SW, et al. Safety and efficacy of nesiritide in pediatric heart failure. $\mathcal{F}$ Card Fail. 2007;13:541-548.
20 Sackner-Bernstein JD, Kowalski M, Fox M, Aaronson K. Short-term risk of death after treatment with nesiritide for decompensated heart failure: a pooled analysis of randomized controlled trials. FAMA. 2005;293:1900-1905.

21 Sackner-Bernstein JD, Skopicki HA, Aaronson KD. Risk of worsening renal function with nesiritide in patients with acutely decompensated heart failure. Circulation. 2005;111:1487-1491.

22 Topol EJ. Nesiritide-not verified. $N$ Engl 7 Med. 2005;353:113-116.

23 Hernandez AF, O'Connor CM, Starling RC, et al. Rationale and design of the Acute Study of ClinicalEffectiveness of Nesiritide in Decompensated Heart Failure Trial (ASCEND-HF). Am Heart 7 . 2009;157:271-277.

24 Law YM, Ettedgui J, Beerman L, Maisel A, Tofovic S. Comparison of plasma B-type natriuretic peptide levels in single ventricle patients with systemic ventricle heart failure versus isolated cavopulmonary failure. Am 7 Cardiol. 2006;98:520-524.

25 Law YM, Keller BB, Feingold BM, Boyle GJ. Usefulness of plasma B-type natriuretic peptide to identify ventricular dysfunction in pediatric and adult patients with congenital heart disease. Am 7 Cardiol. 2005;95:474-478.

26 Sun LS, Dominguez C, Mallavaram NA, Quaegebeur JM. Dysfunction of atrial and B-type natriuretic peptides in congenital univentricular defects. 7 Thorac Cardiovasc Surg. 2005;129:1104-1110.

27 Ozhan H, Albayrak S, Uzun H, Ordu S, Kaya A, Yazici M. Correlation of plasma B-type natriuretic peptide with shunt severity in patients with atrial or ventricular septal defect. Pediatr Cardiol. 2007; 28:272-275.

28 Holmgren D, Westerlind A, Berggren H, Lundberg $\mathrm{PA}$, Wahlander $\mathrm{H}$. Increased natriuretic peptide type B level after the second palliative step in children with univentricular hearts with right ventricular morphology but not left ventricular morphology. Pediatr Cardiol. 2008;29:786-792.

29 Koch AM, Zink S, Singer H, Dittrich S. B-type natriuretic peptide levels in patients with functionally univentricular hearts after total cavopulmonary connection. Eur 7 Heart Fail. 2008;10:60-62.

30 Shih CY, Sapru A, Oishi P, et al. Alterations in plasma B-type natriuretic peptide levels after repair of congenital heart defects: a potential perioperative marker. F Thorac Cardiovasc Surg. 2006;131:632-638.

31 Koch A, Kitzsteiner T, Zink S, Cesnjevar R, Singer H. Impact of cardiac surgery on plasma levels of B-type natriuretic peptide in children with congenital heart disease. Int 7 Cardiol. 2007;114:339-344.

32 Koch A, Zink S, Singer H. B-type natriuretic peptide in paediatric patients with congenital heart disease. Eur Heart 7. 2006;27:861-866.

33 Lechner E, Gitter R, Mair R, et al. Aminoterminal brain natriuretic peptide levels in children and 
adolescents after Fontan operation correlate with congestive heart failure. Pediatr Cardiol. 2008;29: 901-905.

34 Gibson SC, Payne CJ, Byrne DS, Berry C, Dargie HJ, Kingsmore DB. B-type natriuretic peptide predicts cardiac morbidity and mortality after major surgery. Br 7 Surg. 2007;94:903-909.

35 Pene F, Courtine E, Cariou A, Mira JP. Toward theragnostics. Crit Care Med. 2009;37(suppl 1):S50 S58.

36 Hoffman TM, Wernovsky G, Atz AM, et al. Prophylactic intravenous use of milrinone after cardiac operation in pediatrics (PRIMACORP) study. Prophylactic intravenous use of milrinone after cardiac operation in pediatrics. Am Heart 7. 2002;143:1521.

37 Koch A, Singer H. Normal values of B type natriuretic peptide in infants, children, and adolescents. Heart. 2003;89:875-878.

38 Ationu A, Singer DR, Smith A, Elliott M, Burch M, Carter ND. Studies of cardiopulmonary bypass in children: implications for the regulation of brain natriuretic peptide. Cardiovasc Res. 1993;27:15381541.

39 Mair J. Biochemistry of B-type natriuretic peptide-where are we now? Clin Chem Lab Med. 2008;46:1507-1514.

40 Das SR, Abdullah SM, Leonard D, et al. Association between renal function and circulating levels of natriuretic peptides (from the Dallas Heart Study). Am 7 Cardiol. 2008;102:1394-1398.

41 Claudius I, Lan YT, Chang RK, Wetzel GT, Alejos $\mathrm{J}$. Usefulness of B-type natriuretic peptide as a noninvasive screening tool for cardiac allograft pathol- ogy in pediatric heart transplant recipients. $A m \mathcal{F}$ Cardiol. 2003;92:1368-1370.

42 Cowley CG, Bradley JD, Shaddy RE. B-type natriuretic peptide levels in congenital heart disease. Pediatr Cardiol. 2004;25:336-340.

43 Hjortdal VE, Stenbog EV, Ravn HB, et al. Neurohormonal activation late after cavopulmonary connection. Heart. 2000;83:439-443.

44 Koulouri S, Acherman RJ, Wong PC, Chan LS, Lewis AB. Utility of B-type natriuretic peptide in differentiating congestive heart failure from lung disease in pediatric patients with respiratory distress. Pediatr Cardiol. 2004;25:341-346.

45 Suda K, Matsumura M, Matsumoto M. Clinical implication of plasma natriuretic peptides in children with ventricular septal defect. Pediatr Int. 2003;45:249-254.

46 Simsic JM, Scheurer M, Tobias JD, et al. Perioperative effects and safety of nesiritide following cardiac surgery in children. 7 Intensive Care Med. 2006; 21:22-26.

47 Simsic JM, Mahle WT, Cuadrado A, Kirshbom PM, Maher KO. Hemodynamic effects and safety of nesiritide in neonates with heart failure. $\mathcal{F}$ Intensive Care Med. 2008;23:389-395.

48 Mahle WT, Cuadrado AR, Kirshbom PM, Kanter KR, Simsic JM. Nesiritide in infants and children with congestive heart failure. Pediatr Crit Care Med. 2005;6:543-546.

49 Ryan A, Rosen DA, Tobias JD. Preliminary experience with nesiritide in pediatric patients less than 12 months of age. 7 Intensive Care Med. 2008;23:321328. 